\title{
Different Synaptic Channel Kinetics in Sympathetic B and C Neurons of the Bullfrog
}

\author{
Lawrence M. Marshall \\ Department of Physiology, University of North Carolina School of Medicine, Chapel Hill, North Carolina 27514
}

Sympathetic ganglia of the frog contain two types of principal neurons, $B$ and $C$ cells, which are innervated by two distinct classes of cholinergic preganglionic axons, $B$ and $C$ fibers. This study examined and compared the kinetics of nicotinic AChgated channels that produce the fast excitatory postsynaptic currents (EPSCs) in $B$ and $C$ cells. Neurons were identified and voltage-clamped at $-50 \mathrm{mV}, 22^{\circ} \mathrm{C}$. The EPSC decayed as a single exponential for both cell types, but the decay time constants differed considerably; $10.2 \pm 2.3$ msec (mean \pm SD) for $C$ cells and $5.5 \pm 1.1$ msec for B cells. Analysis of ACh-induced membrane current fluctuations revealed spectra that fit singleLorentzian functions and gave estimates of the mean channel open time of $9.8 \pm 2.0 \mathrm{msec}$ and $5.2 \pm 0.9 \mathrm{msec}$ for $\mathrm{C}$ and $\mathrm{B}$ cells, respectively. Thus, the clear difference in EPSC decay rate for these two types of ganglion cells is most likely due to the differences in the mean lifetimes of their synaptic channels.

There is considerable evidence that the time course of synaptic current in skeletal muscle is governed by the rate of closure of endplate ion channels, so that the decay time constant of the current reflects the average channel lifetime (Anderson and Stevens, 1973; Katz and Miledi, 1972, 1973). This role of channel kinetics in the duration synaptic currents becomes apparent in fast and slow contracting types of muscle fibers of lower vertebrates. The decay of the excitatory postsynaptic current (EPC) of slow myofibers is 2- to 3-fold slower than that of fast myofibers, and this difference in macroscopic currents is accompanied by a similar difference in the ACh-gated channel lifetime at their endplates (Dionne and Parsons, 1978, 1981; Miledi and Uchitel, 1981). The purpose of the present study was to examine the possibility that different subclasses of sympathetic neurons may also have synaptic currents of different duration, which could be dictated by the lifetimes of their nicotinic ACh-gated ion channels.

Lumbar sympathetic ganglia of amphibia have two major types of principal neurons, which receive afferent input from one of two distinct classes of cholinergic preganglionic axons (Nishi et al., 1965). The B cells are larger (30-50 $\mu \mathrm{m}$ diameter) and are innervated solely by the fast-conducting $B$ preganglionic fibers $(\sim 2 \mathrm{~m} / \mathrm{sec})$, whereas the smaller C cells $(15-30 \mu \mathrm{m}$ diameter) receive synaptic input from the slow-conducting $C$ fibers $(\sim 0.2 \mathrm{~m} / \mathrm{sec})$. The fast excitatory postsynaptic currents (EPSCs) of B cells have been examined (Kuba and Nishi, 1979; MacDermott et al., 1980), but the properties of the underlying nicotinic ACh-gated channels have not been studied previously. An early hint of differences in the fast excitatory responses of

\footnotetext{
Received May 7, 1985; accepted July 26, 1985.

This work was supported by NIH Grants 17203 and 14899.

Correspondence should be addressed to L. M. Marshall, Ph.D., Department of Physiology, 258 Medical Research Building, 206H, University of North Carolina, Chapel Hill, NC 27514.

Copyright (C) 1986 Society for Neuroscience $0270-6474 / 86 / 020590-04 \$ 02.00 / 0$
}

these two types of ganglionic neurons comes from the observation that the fast EPSP of $\mathrm{C}$ cells has a longer duration than that of B cells (Nishi et al., 1965).

This study examined and compared the fast EPSC and the ACh-gated channel lifetimes of $B$ and $C$ cells. The results show that the EPSC decays about $2 \times$ slower in C cells than in B cells. Spectral analysis of ACh-induced membrane current noise indicates that the slower decay of synaptic current is most likely due to the longer average lifetime of $\mathrm{ACh}$-gated channels in $\mathrm{C}$ cells as compared with B cells.

\section{Materials and Methods}

Adult bullfrogs (Rana catesbeiana) were quickly sacrificed by decapitation after being anesthetized by a $1 \mathrm{hr}$ ice bath. The section of the sympathetic chain containing the $7 \mathrm{th}-10$ th paravertebral ganglia was removed and pinned out in a recording chamber. Following $5 \mathrm{~min}$ incubation with collagenase $(1 \mathrm{mg} / \mathrm{ml}$; Worthington, class CLSPA), the connective tissue over the 9 th and 10th ganglia was dissected away. All experiments were carried out at room temperature $\left(21-23^{\circ} \mathrm{C}\right)$, in Ringer's solution (115 mM NaCl, $2 \mathrm{mM} \mathrm{KCl}, 1.8 \mathrm{~mm} \mathrm{CaCl}, 1 \mathrm{~mm} \mathrm{Na}$ HEPES, pH 7.2) containing $0.5 \mu \mathrm{M}$ atropine sulfate (Sigma) to prevent activation of muscarinic receptors. At this concentration, atropine has no effect on the nicotinic response (MacDermott et al., 1980).

Neurons were impaled by two microelectrodes under visual control using $800 \times$ Hoffman modulation contrast optics, and voltage-clamped by conventional methods (Takeuchi and Takeuchi, 1959). A bricf 1-3 $\mathrm{mV}$ deviation in voltage control often occurred during the rising phase of the fast EPSC. It is unlikely that this deviation produced significant error in the analysis because it vanished before the peak of the EPSC. Electrode noise was minimized by reducing the resistances of the recording and current-passing micropipettes (filled with $4 \mathrm{~m} \mathrm{~K}$-acetate) from 60 to $20 \mathrm{M} \Omega$ by beveling in a slurry of alumina powder (Lederer et al., 1979).

Suction electrodes were applied to the 7 th and 8 th spinal nerves to stimulate preganglionic $\mathrm{C}$ fibers and to the interganglionic nerve trunk above the 7 th ganglion to stimulate preganglionic $B$ fibers. Conduction velocity was estimated by dividing the length of nerve trunk by the response latency (time between the stimulus and the response). Fast EPSCs were digitized at $5-10 \mathrm{kHz}$ and analyzed by a microcomputer. The rclative amplitude of the EPSC was plottcd logarithmically against time after the response peak and fitted by microcomputer to a leastsquares linear regression line. The EPSC decay time constant was computed as the inverse slope of the regression line.

Membrane current noise was produced by iontophoretic application of ACh from a micropipette filled with $2 \mathrm{~m} \mathrm{AChCl} \mathrm{(Sigma).} \mathrm{ACh} \mathrm{was}$ ejected by reducing the braking current to a level that resulted in a mean membrane current of about $0.5-1.5 \mathrm{nA}$ at a clamp potential of -50 $\mathrm{mV}$. Records of membrane current noise $(30-45 \mathrm{sec})$ in the presence and absence (control) of ACh were bandpass-filtered $(0.5-500 \mathrm{~Hz}), 48$ $\mathrm{dB}$ (octave), digitized $(1024 \mathrm{~Hz}$ ), and analyzed by techniques similar to those of Anderson and Stevens (1973). The net power density spectrum of ACh-induced current noise was obtained by subtracting the control noise spectrum from the spectrum obtained in the presence of $\mathrm{ACh}$.

Power density spectra were interpreted by the analysis methods applied in previous studies of $\mathrm{ACh}$-induced current noise (Anderson and Stevens, 1973; Katz and Miledi, 1972). Each spectrum was fitted by eye with a computer-generated Lorentzian function of the form 

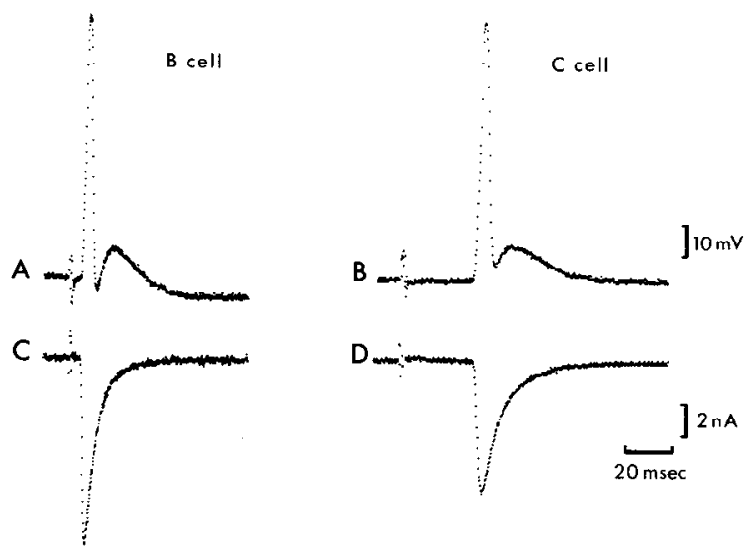

Figure 1. Typical fast excitatory responses of B and C cells. $A$ and $B$, Fast EPSPs and triggered action potentials recorded from a $B$ cell and a $C$ cell before voltage-clamping. $C$ and $D$. The same neurons were voltage-clamped at $-50 \mathrm{mV}$ to show the underlying synaptic currents. Note that the decay of the EPSC is slower for the C cell $(D)$ than for the B cell $(C)$.

$$
S(f)=\frac{S(0)}{1+\left(f / f_{c}\right)^{2}}
$$

where $S(f)$ is the spectral density, $S(0)$ is the spectral density at zero frequency, $f$ is the frequency, and $f_{c}$ is the frequency at which $S(f)$ is half-maximal. The mean open time of the channels was estimated as

$$
\tau=\frac{1}{2 \pi f_{c}}
$$

The single channel conductance was estimated from the equation

$$
\gamma=\frac{S(0) \pi f_{c}}{2 I\left(V_{c}-E_{\mathrm{rev}}\right)}
$$

where $I$ is the mcan $\mathrm{ACh}$-induced membrane current, $V_{c}$ is the clamp potential, and $E_{\text {rev }}$ is the reversal potential for the ACh response. $E_{\text {rev }}$ was assumed to be $-5 \mathrm{mV}$, the approximate value of the reversal potential for the fast EPSC (MacDermott et al., 1980), which has been shown to be essentially the same for B and C cells (Nishi et al., 1965).

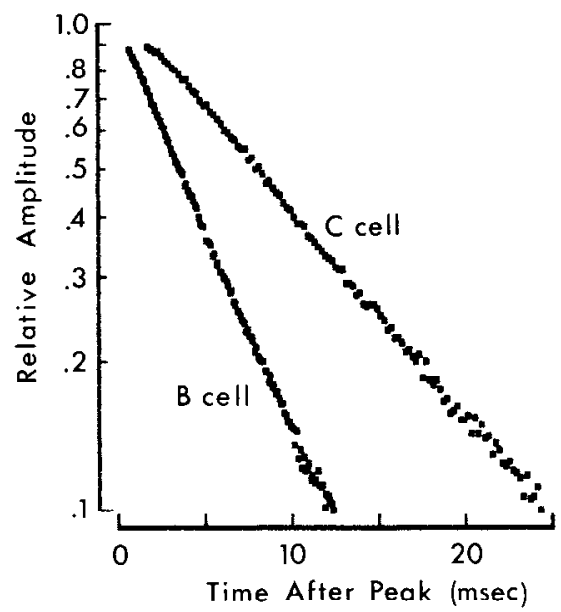

Figure 2. Exponential decay time constants of EPSCs. The relative amplitude of EPSCs of a B and a C cell are plotled on a logarithmic scale as a function of time after the peak. The near linearity of the plots indicates that the decay phases of both types of neurons follow a single exponential. The decay time constant, calculated as the inverse slope, is 10.2 and $5.2 \mathrm{msec}$ for the $\mathrm{C}$ and B cells, respectively $(-50 \mathrm{mV}, 21-$ $\left.23^{\circ} \mathrm{C}\right)$. The peak EPSC amplitudes are $2.63 \mathrm{nA}(\mathrm{C}$ cell) and $2.86 \mathrm{nA}(\mathrm{B}$ cell).

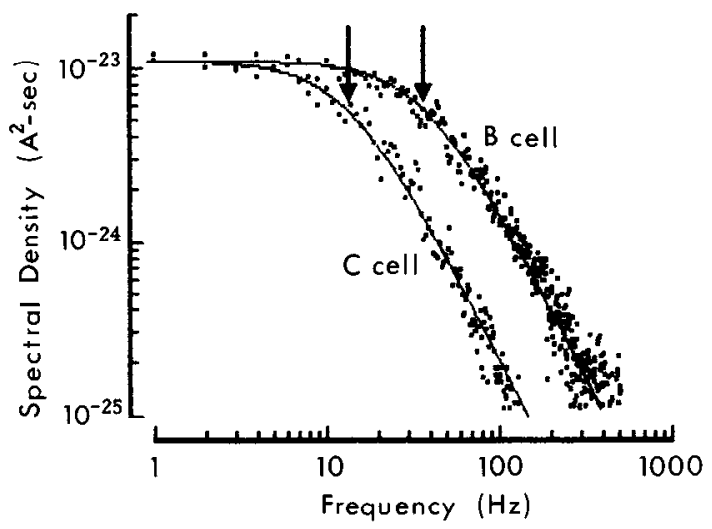

Figure 3. Representative power density spectra of ACh-induced membrane current noise. Each spectrum is fitted with a single Lorentzian function (continuous line). The half-power frequencies (arrows) of 14 and $36 \mathrm{~Hz}$ correspond to mean channel open times of 11.4 and 4.4 msec for the $\mathrm{C}$ and $\mathrm{B}$ cell, respectively $\left(-50 \mathrm{mV}, 21-23^{\circ} \mathrm{C}\right)$.

\section{Results}

\section{Cell identification}

Neurons were selected at random, impaled with two micropipettes, and classified as B or C cells according to the segmental origin of their preganglionic innervation (Libet et al., 1968; Nishi et al., 1965). C cells responded to stimulation of preganglionic $\mathrm{C}$ axons which enter the sympathetic chain at the 7 th and 8th spinal segments, and $B$ cells responded to stimulation of the nerve trunk above the 7 th ganglion, which contains only B-type preganglionic axons. None of the neurons examined responded to stimulation of both types of preganglionic nerve pathways. Preganglionic conduction velocities ranged from 0.1 to $0.6 \mathrm{~m} / \mathrm{sec}$ for C fibers and from 1.2 to $3.5 \mathrm{~m} / \mathrm{sec}$ for $B$ fibers, in agreement with previous studies (Dodd and Horn, 1983; Libet et al., 1968; Nishi et al., 1965).

\section{Fast excitatory responses}

The anatomical features of amphibian autonomic neurons are well suited for voltage-clamp analysis of synaptic currents; there are no dendrites and the synapses are confined mainly to the cell body and the initial segment of the axon (Marshall, 1981;

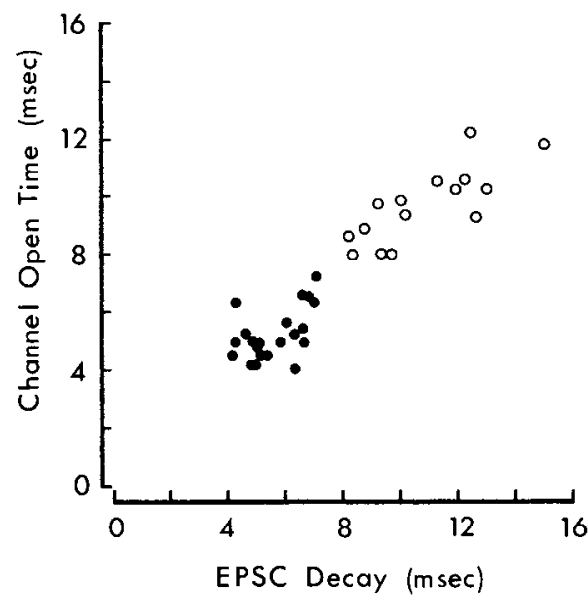

Figure 4. EPSC decay time constant vs mean channel open time. The $\mathrm{C}$ cells (open symbols), as well as the B cells (solid symbols), with slower synaptic currents tend to have longer ACh-gated channel lifetimes. Data are from $15 \mathrm{C}$ cells and $22 \mathrm{~B}$ cells at $-50 \mathrm{mV}, 21-23^{\circ} \mathrm{C}$. A least-squares linear regression line (not shown) fitted to these data has the form: $y=$ $0.77 x+1.12, r=0.94$. 
Taxi, 1961; Weitsen and Weight, 1977). Stable recordings were more frequently obtained from the large cell bodies of $B$ cells than from the smaller C cells; only 28 of over $80 \mathrm{C}$ cells impaled gave recordings that were stable enough for voltage-clamping. Resting potentials, initially on -30 to $-40 \mathrm{mV}$, gradually increased to a stable level of -45 to $-60 \mathrm{mV}$ within $1-3 \mathrm{~min}$ of penetration.

Figure 1, $A$ and $B$, shows typical voltage responses of a $\mathrm{B}$ cell and a $\mathrm{C}$ cell to a single stimulus delivered to the appropriate preganglionic nerve. The longer response latency in the $\mathrm{C}$ cell record reflects the slower conduction velocity of preganglionic C tibers. Except for a slightly lengthened response from the $\mathrm{C}$ cell, the records are similar; the depolarizing fast EPSP immediately triggers a single postsynaptic impulse, then returns to the baseline within 30-50 msec. However when the cells were voltage-clamped, there was a striking difference seen in the duration of the underlying synaptic currents, as shown in Figure $1, C$ and $D$.

This disparity in the decay rates of EPSCs from these two types of ganglion cells is illustrated in the semilogarithmic plots in Figure 2. The near linearity of the plots indicates that EPSCs from both types of neurons decay as a single exponential, but the time constant of decay is about twofold greater in $\mathrm{C}$ cells than in $\mathrm{B}$ cells. The average FPSC decay time constant was $10.2 \pm 2.3 \mathrm{msec}$ (mean $\pm \mathrm{SD} ; n=28$ ) for $\mathrm{C}$ cells and $5.5 \pm$ $1.1 \mathrm{msec}(n=46)$ for B cells. Similar EPSC decay constants for B cells have been reported by Kuba and Nishi (1979) and MacDermott et al. (1980).

\section{Fluctuation analysis}

Spectral analysis of ACh-induced current fluctuations was performed to test the possibility that the slower decay of the EPSC in C cells may be due to slower relaxation kinetics of ACh-gated synaptic channels. Membrane current noise was produced by a steady iontophoretic application of $\mathrm{ACh}$ from a micropipette positioned 30-40 $\mu \mathrm{m}$ above the neuronal surface. Noise records were discarded if they were unstable or contained spontaneous miniature EPSCs. Fifteen of $28 \mathrm{C}$ cells and 22 of $36 \mathrm{~B}$ cells examined in this manner produced noise records that were suitable for spectral analysis. Figure 3 provides examples of the ACh noise spectra from a $C$ cell and a $B$ cell for comparison. The ACh noise spectrum of the C cell, like that of the B cell, is adequately fit by a single Lorentzian function. This indicates that the fluctuations probably arose from a single kinetic class of ion channels. Differences in half-power frequencies (Fig. 3, arrows) for the spectra suggest that the average time a channel spends in the open state is about twice as long for $C$ cells as for $B$ cells. The average estimated channel lifetime of $C$ cells was $9.8 \pm 2.0 \mathrm{msec}$ (mean $\pm \mathrm{SD}$ ) compared with $5.2 \pm 0.9 \mathrm{msec}$ for B cells. The estimated single channel conductance of $16.9 \pm 2.7$ pS for C cells was not significantly different from the $17.3 \pm$ $3.3 \mathrm{pS}$ for B cells ( $p>0.1$; Student's $t$ test).

The nearly twofold difference in the average channel lifetimes for $\mathrm{C}$ and $\mathrm{B}$ cells closely matches the difference in their average EPSC decay time constants. Figure 4 illustrates that, in general, those neurons with slower synaptic currents tended to have longer channel lifetimes. This supports the idea that the decay of the synaptic current is limited by the rate of synaptic channel closure and that differences in channel lifetime most likely account for the differences in the duration of fast synaptic currents in $\mathrm{B}$ and $\mathrm{C}$ neurons.

\section{Discussion}

The principal finding of this study is that, in bullfrog sympathetic ganglia, the fast EPSC of $C$ neurons is longer in duration than that of $\mathrm{B}$ neurons, most probably owing to the longer average lifetime of $\mathrm{ACh}$-gated channels in $\mathrm{C}$ neurons. Experimental evidence supporting this interpretation is as follows: (1)
The average exponential decay time constant of the EPSC of C neurons is about twofold greater than that of $B$ neurons; and (2) analysis of ACh-induced membrane current noise revealed a similar twofold difference in mean channel open time, which closely matches the EPSC decay time constant for both types of ganglion cells.

These two classes of frog sympathetic neurons have differences in synaptic properties other than those presented here. The slow muscarinic synaptic response found in C cells is inhibitory, while that of the B cell is excitatory (Horn and Dodd, 1981; Nishi and Koketsu, 1968; Tosaka et al., 1968). Also, the peptide similar to luteinizing hormone releasing hormone that mediates the late slow synaptic potentials is present only in the preganglionic $\mathrm{C}$ fibers (Jan and Jan, 1983). In addition, the bullfrog sympathetic ganglia contain small intensely fluorescent (SIF) cells which, like C neurons, are innervated solely by preganglionic C fibers (Dunn and Marshall, 1985). It will be of interest to examine the synaptic currents of these SIF cells for comparison with the principal neurons of the ganglia.

The similarity between the ACh-gated channels of subclasses of skeletal muscle fibers and these two types of sympathetic neurons is striking. Slow-contracting myofibers, like sympathetic $C$ cells, are innervated by slow-conducting axons and have relatively long channel lifetimes (Dionne and Parsons, 1978, 1981; Miledi and Uchitel, 1981). In contrast, fast-contracting myofibers, as well as B cells, receive synaptic input from fastconducting axons and have ACh-gated channels with comparatively short lifetimes. Although the functional significance of this difference in synaptic channel kinetics is unknown, it raises the possibility that expression of postsynaptic channel properties may be specified by the particular type of presynaptic nerve.

\section{References}

Anderson, C. R., and C. F. Stevens (1973) Voltage clamp analysis of end-plate current fluctuations at frog neuromuscular junction. J. Physiol. (Lond.) 235: 655-691.

Dionne, V. E., and R. L. Parsons (1978) Synaptic channel gating differences at snake twitch and slow neuromuscular junctions. Nature 274: 902-904

Dionne, V. E., and R. L. Parsons (1981) Characteristics of the acetylcholine-operated channel at twitch and slow fibre neuromuscular juctions of the garter snake. J. Physiol. (Lond.) 310: 145-158.

Dodd, J., and J. P. Horn (1983) A reclassification of B and C neurones in the ninth and tenth paravertebral sympathetic ganglia of the bullfrog. J. Physiol. (Lond.) 334: 255-269.

Dunn, P. M., and L. M. Marshall (1985) Innervation of small intensely fluorescent cells in frog sympathetic ganglia. Brain Res. 339: 371374.

Horn, J. P., and J. Dodd (1981) Monosynaptic muscarinic activation of $\mathrm{K}$ conductance underlies the slow inhibitory postsynaptic potential in sympathetic ganglia. Nature 292: 625-627.

Jan, L. Y., and Y. N. Jan (1983) Peptidergic transmission in sympathetic ganglia of the frog. J. Physiol. (Lond.) 327: 219-246.

Katz, B., and R. Miledi (1972) The statistical nature of the acetylocholine potential and its molecular components. J. Physiol. (Lond.) 224: 665-699.

Katz, B., and R. Miledi (1973) The binding of acetylcholine to receptors and its removal from the synaptic cleft. J. Physiol. (Lond.) 231: $549-574$.

Kuba, K., and S. Nishi (1979) Characteristics of the fast excitatory postsynaptic current in bullfrog sympathetic ganglion cells. Effects of membrane potential, temperature, and $\mathrm{Ca}$ ion. Pfluegers Arch. 378: 205-212.

Libet, B., S. Chichibu, and T. Tosaka (1968) Slow inhibitory responses and excitability in sympathetic ganglia of the bullfrog. J. Neurophysiol. 31: 383-395.

Iederer, W. J., A. J. Spindler, and D. A. Eisner (1979) Thick slurry beveling. Pfluegers Arch. 381: 287-288.

MacDermott, A. B., E. A. Connor, V. E. Dionne, and R. L. Parsons (1980) Voltage clamp study of fast excitatory synaptic currents in bullfrog sympathetic ganglion cells. J. Gen. Physiol. 75: 39-60. 
Marshall, L. M. (1981) Synaptic localization of $\alpha$-bungarotoxin binding which blocks nicotinic transmission at frog sympathetic neurons. Proc. Natl. Acad. Sci. USA 78: 1948-1952.

Miledi, R., and O. D. Uchitel (1981) Properties of postsynaptic channels induced by acetylcholine in different frog muscle fibres. Nature 291: $162-165$.

Nishi, S., and K. Koketsu (1968) Analysis of slow inhibitory postsynaptic potential of bullfrog sympathetic ganglia. J. Neurophysiol. 31: 717-728.

Nishi, S., H. Soeda, and K. Koketsu (1965) Studies on sympathetic $B$ and $C$ neurons and patterns of preganglionic innervation. J. Cell. Comp. Physiol. 66: 19-32.
Takeuchi, A., and N. Takeuchi (1959) Active phase of frog's end-plate potential. J. Neurophysiol. 22: 395-411.

Taxi, J. (1967) Observations on the ultrastructure of ganglionic neurons and synapses of the frog Rana esculenta. In The Neuron, $\mathbf{H}$. Hyden, ed., pp. 221-254, Elsevier, New York.

Tosaka, T., S. Chichibu, and B. Libet (1968) Intracellular analysis of slow inhibitory and excitatory postsynaptic potentials in sympathetic ganglia of the frog. J. Neurophysiol. 31: 396-409.

Weitsen, H. A., and F. F. Weight (1977) Synaptic innervation of sympathetic ganglion cells in the bullfrog. Brain Res. 128: 97-211. 